\title{
Discerning “Flavors" of Drought Using Climate Extremes Indices
}

\author{
Michael A. CRIMMINS \\ Department of Soil, Water, and Environmental Science, The University of Arizona, Tucson, Arizona \\ Daniel B. Ferguson And Alison M. Meadow \\ Institute of the Environment, The University of Arizona, Tucson, Arizona \\ JEREMY L. WEISS \\ School of Natural Resources and the Environment, The University of Arizona, Tucson, Arizona
}

(Manuscript received 9 August 2016, in final form 20 December 2016)

\begin{abstract}
Monitoring drought conditions in arid and semiarid regions characterized by high levels of intra- and interannual hydroclimatic variability is a challenging task. Typical drought-monitoring indices that are based on monthly-scale data lack sufficient temporal resolution to detect hydroclimatic extremes and, when used operationally, may not provide adequate indication of drought status. In a case study focused on the Four Corners region of the southwestern United States, the authors used recently standardized World Meteorological Organization climate extremes indices to discern intra-annual hydroclimatic extremes and diagnose potential drought status in conjunction with the simple metric of annual total precipitation. By applying datareduction methods to a suite of metrics calculated using daily data for 1950-2014, the authors identified five extremes indices that provided additional insight into interannual hydroclimatic variability. Annual time series of these indices revealed anomalous years characterized by shifts in the seasonal distribution of precipitation and in the intensity and frequency of individual events. The driest 4 -yr intervals over the study period, characterized by similar annual and interval total precipitation anomalies, represent dramatically different assemblages of index values, which are interpreted as different "flavors" of drought. In turn, it is expected that varying drought impacts on ecosystems, agricultural systems, and water resources would emerge under these different flavors of drought. Results from this study indicate that operational drought monitoring and historical drought assessments in arid and semiarid regions would benefit from the additional insight that daily-based hydroclimatic extremes indices provide, especially in light of expected climate change-driven changes to the hydrologic cycle.
\end{abstract}

\section{Introduction}

Arid and semiarid regions have low mean annual precipitation but also often have high amounts of spatial and temporal variability in the precipitation that does fall (Noy-Meir 1973; Davidowitz 2002). This inherent variability makes defining and monitoring drought conditions over time very difficult, hampering efforts to develop effective drought-monitoring, response, and mitigation plans. Drought indices typically use monthly-scale data and often focus on moving windows like in the standardized precipitation index (SPI; McKee et al. 1995) or integrate conditions over seasonal and longer time scales

Corresponding authore-mail: Michael A. Crimmins, crimmins@ email.arizona.edu like in the Palmer drought severity index (PDSI; Heim 2002). The seasonal timing, frequency, and intensity of precipitation events can often be as important as or more important than precipitation totals tracked in typical indices relative to different types of drought impacts on ecosystems and hydrological conditions (Holden et al. 2007; Dettinger et al. 2011; Hottenstein et al. 2015; Moran et al. 2014). Holden et al. (2007) found the timing and intensity of precipitation events rather than precipitation totals to be the best predictors of historical variability in wildfire severity in a southwestern U.S. forest ecosystem. Similar results have been found in semiarid grassland ecosystems where metrics measuring precipitation timing, intensity, and frequency were all better predictors of overall soil moisture status and plant growth at multiple time scales (Loik et al. 2004; Lauenroth and Bradford 
2012; Zhang et al. 2013; Hottenstein et al. 2015; Moran et al. 2014; Gremer et al. 2015; Barnes et al. 2016). Soil moisture levels are often cited as the best indicator of potential drought status given their direct connection to plant health in ecosystems and agricultural systems, fuel moisture levels, and interactions with surface and subsurface hydrological conditions, but observations are very limited, and new networks are expensive to install and maintain (Legates et al. 2011; Quiring et al. 2016). Intraannual precipitation variability exerts a strong influence on soil moisture status in arid and semiarid climates and in turn can be a large factor in controlling levels of drought and water stress (Loik et al. 2004). Strategies to gauge and track intra-annual precipitation variability using existing networks of daily precipitation observations offer a simple approach to assess potential soil moisture-related drought stress situations in these regions.

Climate indices to track shifts and trends in temperature and precipitation extremes have been recently introduced and standardized to support regional climate assessments and modeling efforts that are focused on climate extremes (Zhang et al. 2011). These indices were designed to be broadly applicable and easily calculated from daily data, offering the potential to capture oftensubtle shifts in the timing, intensity, and frequency of precipitation as well as cold and warm temperature extremes (New et al. 2006; Arriaga-Ramírez and Cavazos 2010; Zhang et al. 2011; Booth et al. 2012). The IPCC (2012) notes that increasing extremes are pronounced in modeling projections and may lead to shifts in hydroclimatic variability such as increasing numbers of dry days and longer dry spells in some regions, including the western United States. Some of these indices have been incorporated into recent ecosystem studies as well, as it has been noted that precipitation extremes perform better at explaining ecosystem productivity and emergent drought impacts (Zhang et al. 2013; Hottenstein et al. 2015; Moran et al. 2014). Even though these indices to date have been largely applied in assessments of regional climate change and in modeling-output studies, they have direct utility in drought monitoring and as complementary drought indices to track subtle shifts in intra-annual hydroclimatic variability. Utilizing these indices in operational drought monitoring offers the potential for improving drought early-warning systems as well as helping to better diagnose and define drought conditions that are unique to the highly variable climates of arid and semiarid regions. This paper highlights a case study in which climate extremes indices were used to examine historical drought variability across tribal lands of the Four Corners region of the southwestern United States. The results provide additional insight into the character and nature of past droughts in the region relative to the unique resource-management challenges that exist in this area, using a novel approach that can be employed in other regions with arid and seasonal climates.

\section{Study area: Four Corners region of the southwestern United States}

The Four Corners region (Fig. 1) in the southwestern United States is home to several Native American communities, including the Hopi Tribe and the Navajo Nation, both of whom have been heavily impacted by ongoing drought conditions that extend back to the late 1990s (Crimmins et al. 2013, 2015; Ferguson et al. 2011, 2016; Meadow et al. 2013). Declining levels in surface water resources and springs, decreasing vegetation cover and increasing soil erosion, and impacts on dryland agricultural activities have all emerged as severe drought impacts across the region over the past two decades (Faulstich et al. 2013; Ferguson et al. 2016).

Since 2009, we have collaborated with the Hopi Department of Natural Resources (HDNR) on a project to understand and monitor drought conditions in the Four Corners region. The initial concern of the HDNR in contacting authors Crimmins and Ferguson was to obtain help in improving hydroclimatic monitoring across the region, because they did not think that drought conditions were accurately portrayed in the U.S. Drought Monitor. The HDNR is responsible for managing rangelands, wildlife, and some water resources on the 647500 ha of the Hopi Reservation. As part of our collaboration, we worked closely with HDNR resource managers and also carried out a series of interviews about drought with a range of Hopi drought stakeholders both within and outside the HDNR, which led to insights about the unique management issues and hydroclimatic information needs related to timing and frequency of precipitation (Ferguson et al. 2016).

The arid to semiarid climate of the region and the inherently high levels of seasonal and interannual variability in precipitation make defining and tracking drought conditions difficult. Total precipitation amounts are often less important than the seasonal timing and frequency of precipitation events relative to drought impacts like wildfire risk, invasive-species encroachment, rangeland conditions, and dryland agriculture (Dominguez and Kolm 2005; Holden et al. 2007; Draut et al. 2012; Ferguson et al. 2016). The average annual cumulative precipitation curve shown in Fig. 2 illustrates the overall low annual precipitation amount typical to the region and also the distinct seasonal transitions in hydroclimate throughout the year. Each season has distinct importance from an ecosystem-service and resource-management perspective relating to local water resources and agroecosystems 


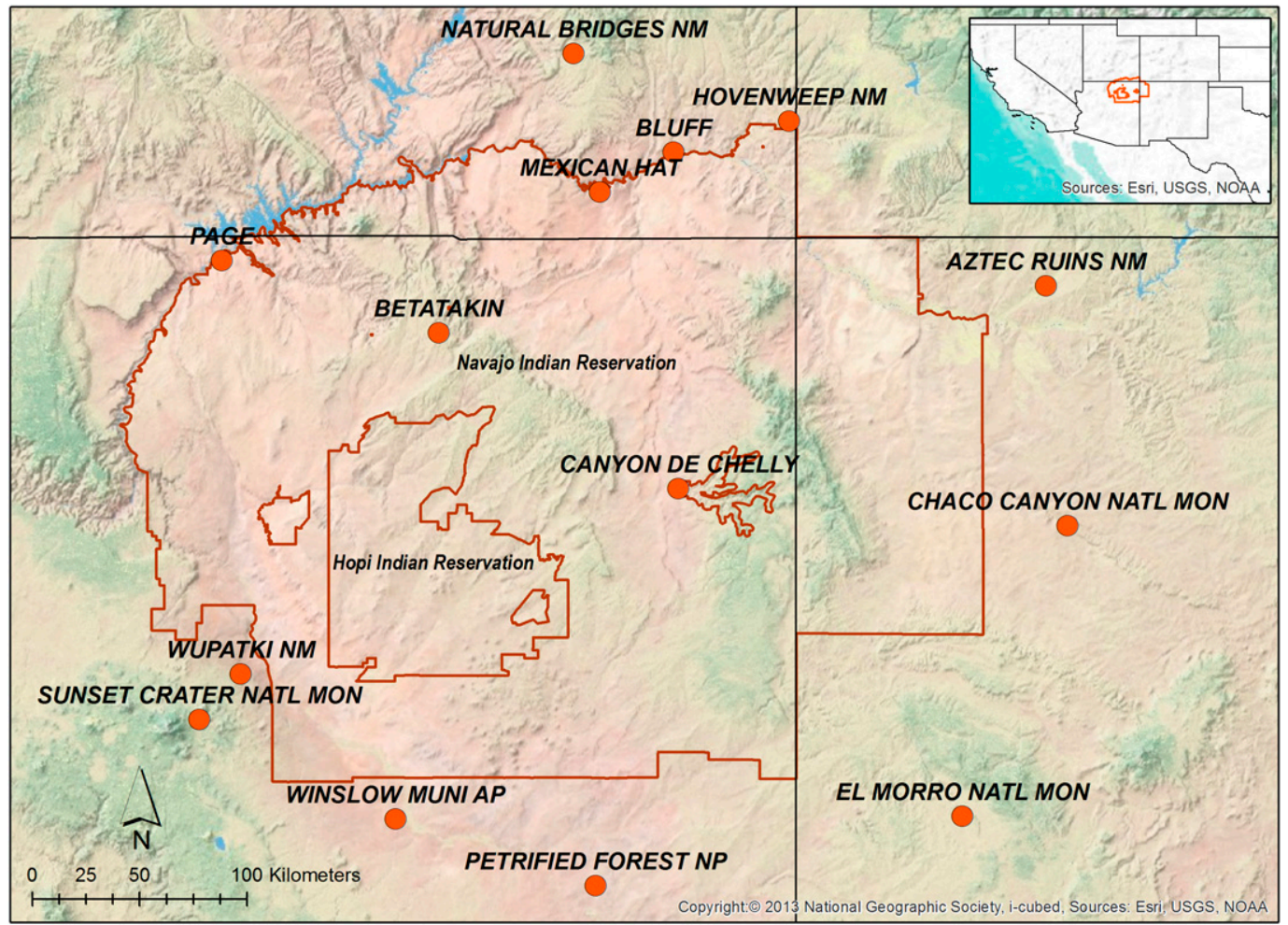

FIG. 1. Study area encompassing the Four Corners region of the southwestern United States, including boundaries for the Hopi Reservation and Navajo Nation and locations of NOAA GHCN stations (orange circles) used in climate analyses. Eastern areas of the Navajo Nation, which are of mixed federal and private ownership and management, are not shown on this map.

(Meadow et al. 2013; Ferguson et al. 2016; Fig. 2). Coolseason precipitation is typically associated with frontal storm systems and can bring high-elevation snow and soaking rains important to local water resources. Summer convective storms associated with the North American monsoon system bring critically timed moisture that ends the wildfire season and supports warm-season grasses that drive forage production but also can bring flooding rains (Hereford and Webb 1992; Sheppard et al. 2002; Finger and Morehouse 2007). Schwinning et al. (2008) note that the seasonal-transitional climate of this region that is due to its geographic location and topographic relief make it especially vulnerable to high levels of seasonal-tointerannual variability and acute drought impacts.

Through interviews with drought stakeholders in the Four Corners region, we found that the timing of precipitation throughout the year is particularly important. For example, late-winter precipitation (usually in the form of snow) increases soil moisture in time for planting early bean crops in the spring. Without the spring soil moisture, farmers may have to haul water, at considerable time and expense, to support their crops. Dryland farmers in the region also rely on monsoon storms in the summer to aid crop growth before harvest in late
September or October. Our interviews and other recent work with Hopi farmers (Rhoades 2013) have recorded farmers' concerns that these key storms seem to be coming later in the autumn than is ideal.

\section{Methods}

\section{a. Data}

To calculate climate extremes indices for examination in this study, long-term climate records with daily resolution were required. Fourteen stations in and around the tribal lands of the Four Corners region were selected from the NOAA Global Historical Climate Network (GHCN) database (Menne et al. 2012) on the basis of limited missing observations (generally less than $25 \%$ missing in any given year) and completeness of record over the 1950-2014 period (Fig. 1, Table 1). Five of the 14 stations have records shorter than the 1950-2014 study period but were included to improve the geographic coverage of observations across the study region. We calculated 12 precipitation extremes indices on the basis of Klein Tank et al. (2009) as well as an additional seasonality metric (day of year with $50 \%$ of cumulative annual total 


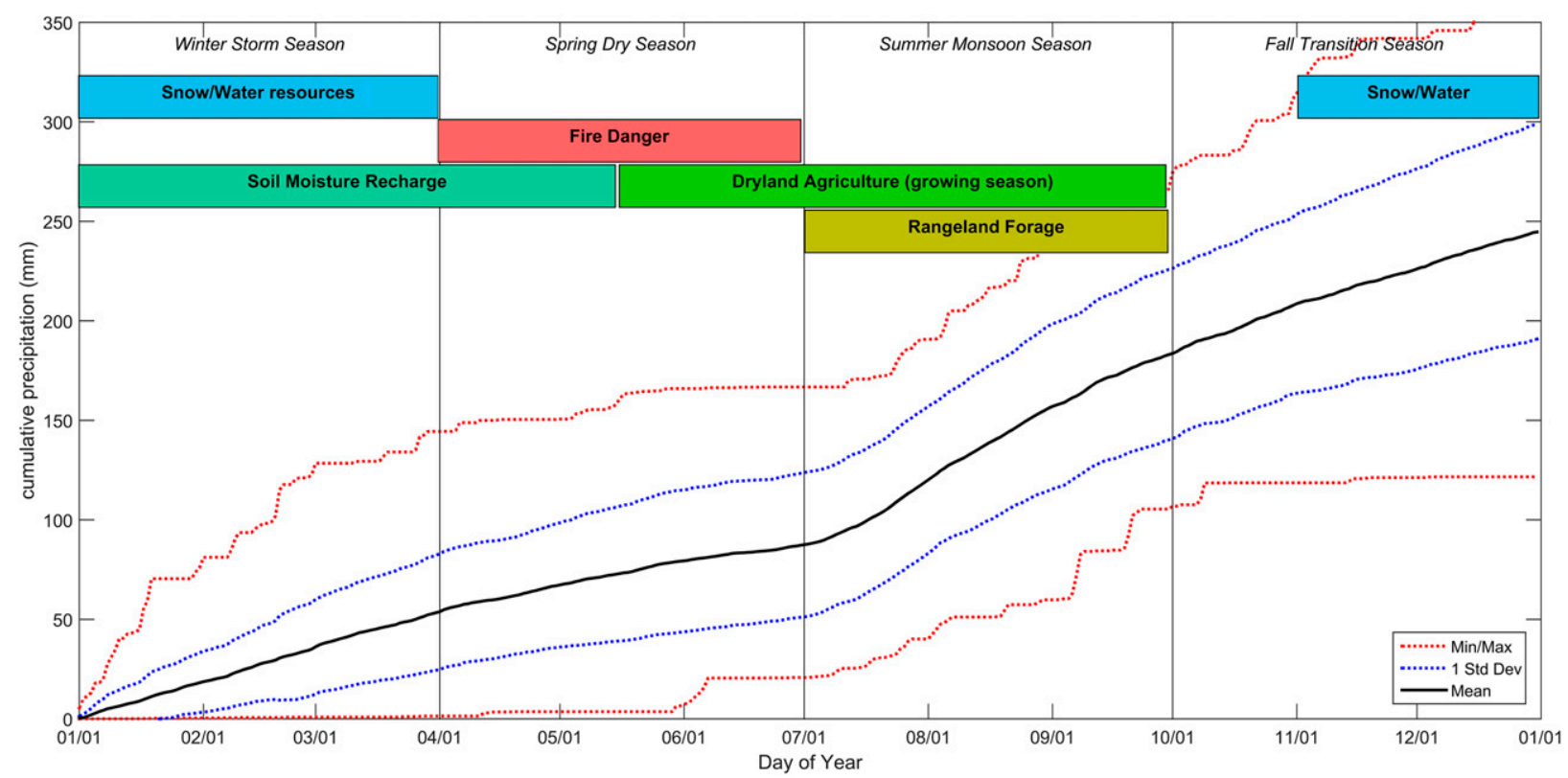

FIG. 2. Regional composite average daily cumulative precipitation developed from 14 NOAA GHCN stations on the Hopi Reservation and Navajo Nation over the period of 1950-2014 (solid black line). The minimum and maximum (red dashed lines) and 1 standard deviation above and below the mean (blue dashed lines) of daily cumulative precipitation totals as based on regional composite values are also depicted. Seasons and key resource-management concerns derived from regional fieldwork and interviews with stakeholders are shown in boxes near the top of the figure (Meadow et al. 2013; Ferguson et al. 2016).

precipitation) for each station for each year in the period of record. Annual total precipitation and annual average temperature were also retained for each station year. Years at a station with more than $10 \%$ of the observations missing were set to missing for the entire year for each index calculation.

\section{b. Climate extremes indices}

We created a regional composite annual time series for each index using the standardized anomaly index approach put forth by Katz and Glantz (1986). The station-level annual time series for each index was converted into standardized anomalies ( $z$ scores) using 1961-90 as the common reference period for the calculation of mean and standard deviation values. We then averaged the standardized anomalies for the 14 stations into a single regional composite time series for each index. The mean and standard deviation values for each station-level anomaly calculation were retained and averaged to derive a single, global mean and standard deviation for each index. This approach minimizes the effect of missing data and stations with

TABLE 1. NOAA GHCN stations used in this study on the Hopi Reservation and Navajo Nation in the Four Corners region of the southwestern United States.

\begin{tabular}{|c|c|c|c|c|}
\hline Station & Lat & Lon & Elev (m) & Period of record used \\
\hline Aztec Ruins National Monument, NM & $36.84^{\circ}$ & $-108.00^{\circ}$ & 1720 & 1950-2014 \\
\hline Betatakin, AZ & $36.68^{\circ}$ & $-110.54^{\circ}$ & 2221 & 1950-2014 \\
\hline Bluff, UT & $37.28^{\circ}$ & $-109.56^{\circ}$ & 1316 & 1950-2014 \\
\hline Canyon de Chelly, AZ & $36.15^{\circ}$ & $-109.54^{\circ}$ & 1710 & 1970-2014 \\
\hline Chaco Canyon National Monument, NM & $36.03^{\circ}$ & $-107.91^{\circ}$ & 1882 & 1950-2014 \\
\hline El Morro National Monument, NM & $35.04^{\circ}$ & $-108.35^{\circ}$ & 2202 & 1950-2014 \\
\hline Hovenweep National Monument, UT & $37.39^{\circ}$ & $-109.08^{\circ}$ & 1597 & $1957-2014$ \\
\hline Mexican Hat, UT & $37.15^{\circ}$ & $-109.87^{\circ}$ & 1252 & 1950-2014 \\
\hline Natural Bridges National Monument, UT & $37.61^{\circ}$ & $-109.98^{\circ}$ & 1984 & $1965-2014$ \\
\hline Page, AZ & $36.92^{\circ}$ & $-111.45^{\circ}$ & 1302 & 1957-2012 \\
\hline Petrified Forest National Park, AZ & $34.80^{\circ}$ & $-109.89^{\circ}$ & 1660 & $1950-2014$ \\
\hline Sunset Crater National Monument, AZ & $35.37^{\circ}$ & $-111.54^{\circ}$ & 2128 & 1969-2014 \\
\hline Winslow Municipal Airport, AZ & $35.03^{\circ}$ & $-110.72^{\circ}$ & 1489 & $1950-2014$ \\
\hline Wupatki National Monument, AZ & $35.52^{\circ}$ & $-111.37^{\circ}$ & 1496 & 1950-2014 \\
\hline
\end{tabular}


TABLE 2. Final climate extremes indices selected for examination in this study on the Hopi Reservation and Navajo Nation in the Four Corners region of the southwestern United States.

\begin{tabular}{lll}
\hline \multicolumn{1}{c}{ Index } & \multicolumn{1}{c}{ Description } & \multicolumn{1}{c}{ Units } \\
\hline PRCPTOT & Annual total precipitation & $\mathrm{mm}$ \\
RX1day & Annual max 1-day precipitation & $\mathrm{mm}$ \\
RX5day & $\begin{array}{c}\text { Annual max consecutive 5-day } \\
\text { precipitation }\end{array}$ & $\mathrm{mm}$ \\
& Max no. of consecutive dry days & days \\
CDD & $\begin{array}{l}\text { Simple daily intensity index: } \\
\text { average precipitation on wet }\end{array}$ & mm day \\
SDII & $\quad$ days ( $>0.254$ mm $)$ & \\
& $\begin{array}{l}\text { Day of year with 50\% of cumulative } \\
\text { annual total precipitation }\end{array}$ & day \\
&
\end{tabular}

different periods of record contributing to regional signal (Katz and Glantz 1986; Balling and Wells 1990). These values were then used to transform the regional composite standardized anomaly values back into the original units of each index. The calendar year was used for the annual time series to match other historical drought assessments conducted across the region (e.g., Hereford et al. 2002; Breshears et al. 2005) but could be readily adjusted to the water year with some minor impact on the temporal variability of the different metrics.

To examine the correlation structure of the regional composite precipitation indices and to identify a subset of the indices that contribute additional explained variance in the interannual signal of hydroclimatic variability beyond total precipitation, we used principal components analysis. The first six principal components explaining $95 \%$ of the variance were retained for further analysis. We applied a varimax rotation to these components and then correlated them with the original index time series. The highest-correlating index with each rotated principal component time series was then used as a key index, contributing additional information on interannual hydroclimatic variability beyond total precipitation alone. The key, selected variables, including total annual precipitation, are listed along with their abbreviation definitions in Table 2 and describe different elements of hydroclimatic variability that can be used to diagnose potential latent drought situations that arise because of unusually long dry spells (CDD), low effective precipitation as a result of accumulations occurring in a few large events (RX1day, RX5day, and SDII), and large shifts in the seasonality of precipitation accumulations that could signal lack of soil moisture at critical times in the annual cycle (P50DAY). Even though these indices are presented as annual values, they can be used to infer whether subannual, shorter-term drought conditions may have been present within the year because of shifts in the timing, intensity, and frequency of precipitation. These types of soil moisture-related drought impacts would be more akin to "agricultural" droughts, which occur on the order of months to seasons, even though the time scale of analysis is at the annual scale. The lack of systematically collected drought-impact data for the study period in this region precluded a rigorous evaluation of the type and time scale of drought impacts to which each index best relates, but studies referenced previously using similar indices lend credence that they relate to soil moisture-related impacts such as seasonal vegetation production and stress, wildfire activity, and the effectiveness of precipitation at recharging and maintaining soil moisture levels (Holden et al. 2007; Dettinger et al. 2011; Zhang et al. 2013; Hottenstein et al. 2015; Moran et al. 2014).

\section{c. Hydroclimatic extremes index}

We developed a hydroclimatic extremes index (HCEI) to identify years in which multiple extremes may be contributing to especially unusual shifts in the timing, frequency, and intensity of precipitation that could mask potential drought conditions that are not readily evident in simple precipitation totals. Each of the key climate extremes indices was rescaled to a rank percentile value and summed for each year. To capture the magnitude of shifts in timing, the absolute difference in P50DAY from median was used in the percentile rank calculation, meaning that very early or very late dates would have high percentile ranks. The maximum theoretical HCEI value is then 5, which would indicate that each metric was the most extreme value relative to its own time series.

\section{Results and discussion}

\section{a. Interannual variability in precipitation relative to climate extremes indices}

Regional composite annual precipitation is shown in Fig. 3a and depicts substantial amounts of interannual variability around the median of $240 \mathrm{~mm}$, with the driest year being $1950(121 \mathrm{~mm})$ and the wettest year being 1957 (355 mm). This pattern of interannual variability is consistent with other studies that describe protracted, multiyear drought periods in the early 1950s and 2000s as well as an extended pluvial that persisted through much of the 1980s (Hereford et al. 2002; Breshears et al. 2005; Weiss et al. 2009; Faulstich et al. 2013). Much of the interannual variability over this period has been linked to the impact of El NiñoSouthern Oscillation (ENSO) on wintertime precipitation patterns (Redmond and Koch 1991; Cayan 

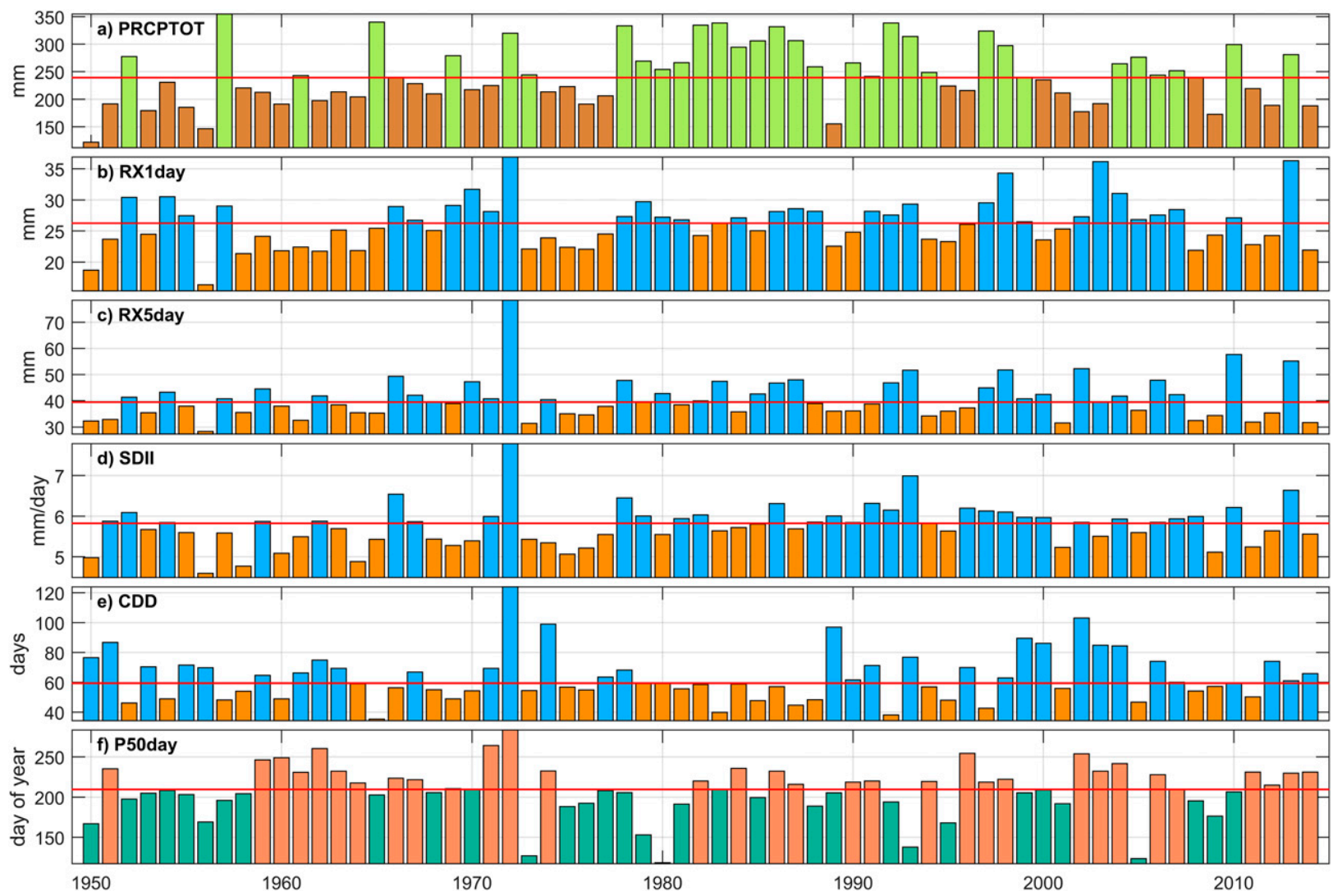

FIG. 3. (a) Total annual precipitation (below median: brown; above median: green), (b)-(e) standard climate extremes indices using codes from Table 2 (below median: orange; above median: blue), and (f) custom seasonality metric (later than median: red; earlier than median: teal) for 1950-2014. Red horizontal lines indicate median values.

et al. 1999) and Pacific Ocean sea surface temperaturedriven decadal variability at longer time scales (Dai 2013). The individual climate extremes indices shown in Figs. 3b-f add further insight into the nature of the subannual precipitation variability relative to the annual totals depicted with PRCPTOT (defined in Table 2). For example, the extended pluvial from the late 1970s to the late 1980s had consistently below-median dry spell lengths (CDD) but a mix of above- and below-median RX1day, RX5day, and SDII values, indicating that some years had more of their annual precipitation in fewer, more intense events even though the annual totals are similar. In addition, P50DAY indicates that the timing of the bulk of cumulative precipitation was variable from year to year over this period, with some years shifted toward winter- or summer-season-dominated precipitation events. Both 1980 and 1988 had near-median precipitation, but 1980 received one-half of its precipitation by day 118 (late April) versus day 188 (early July) in 1988. These different mixes of timing, frequency, and intensity of precipitation events represent substantially different intra-annual hydroclimatic regimes even though annual total precipitation is above median and similar over the period.

\section{b. Variability in the hydroclimatic extremes index}

Figure 4 shows annual HCEI values, with the lowest occurring in 1958 (0.83) and the highest in 1972 (4.95). There is a slight upward but nonsignificant trend (Kendall tau- $b=0.14$; significance level $p=0.09$ ) over the study period, with generally lower values in the $1950 \mathrm{~s}$ and early 1960s and higher values in the 1990s and early 2000s. PRCPTOT (Fig. 3a) is significantly correlated with both ENSO [oceanic Niño index (ONI) -3-month running mean of Niño 3.4 SST anomalies: correlation coefficient $r=0.42 ; p<0.001]$ and the Pacific decadal oscillation (PDO) [PDO index (Mantua et al. 1997): $r=-0.51 ; p<0.001]$, but the HCEI values are not significantly correlated with either index (ONI: $r=0.13$, with $p=0.28$; PDO: $r=-0.18$, with $p=0.13$ ). The HCEI is capturing a different, but complementary, portrait of interannual and decadal variability in hydroclimatic conditions over this region during a period often simply characterized as intervening wet and dry 


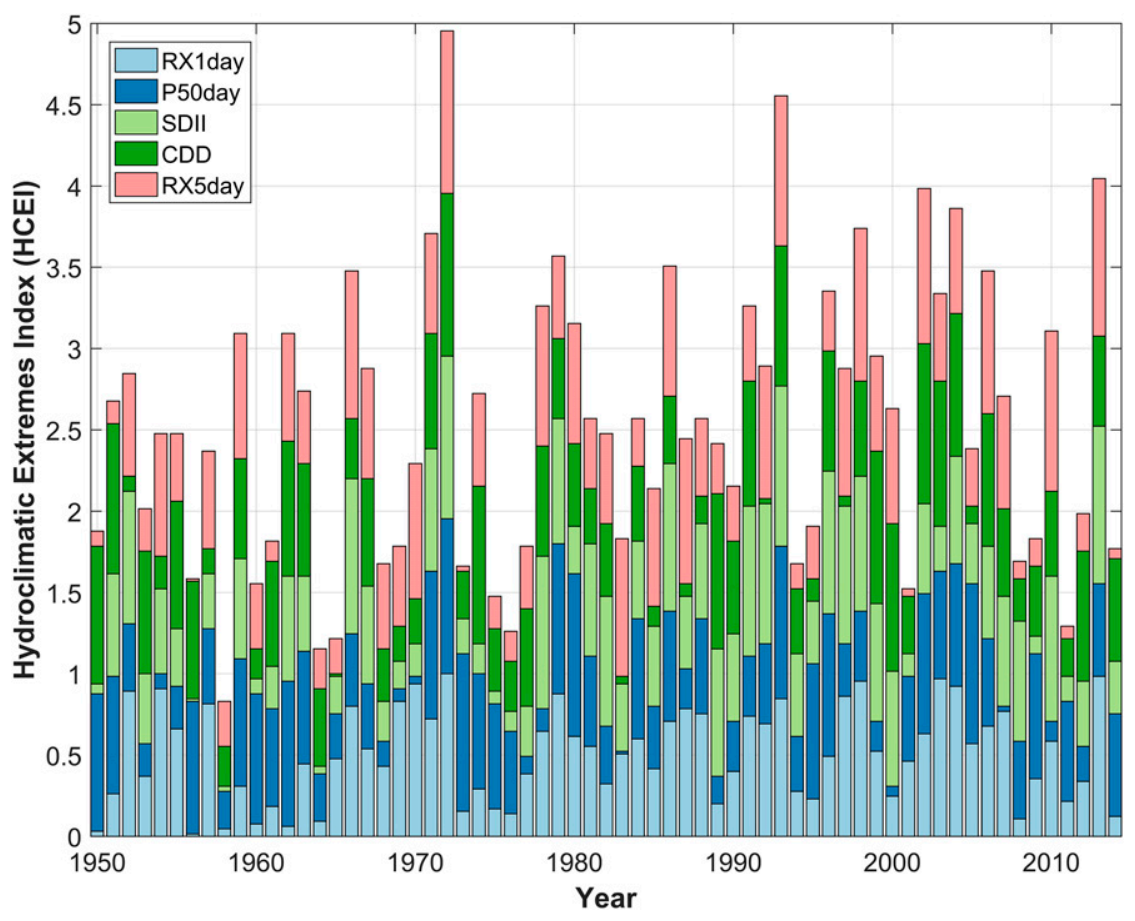

FIG. 4. Annual HCEI values, composed of percentile ranks (0-1) for five extremes indices (listed in Table 2) for 1950-2014.

periods controlled by ENSO and decadal variability in Pacific Ocean SSTs (Seager and Vecchi 2010; Dai 2013). For example, the extended pluvial from 1978 to 1988 had an average HCEI of 2.7, indicating that the combination of individual extremes metrics was neither extremely high nor low, representing an overall relative evenness in precipitation intensity, frequency, and timing. Most individual metrics were near median values for each year in this period, indicating that this wet period was not necessarily driven by a handful of extremeprecipitation events but by an overall increase in the frequency of precipitation events distributed throughout the year. We expect that this pattern in precipitation variability was more beneficial to recharging soil moisture, reducing wildfire risk, and supporting waterlimited ecosystems and agricultural systems (Swetnam and Betancourt 1998; Hereford et al. 2002, 2006).

\section{c. Comparing the 1950s and 2000s drought periods}

We will evaluate two multiyear drought periods with exceptionally low annual precipitation that stand out in the regional precipitation time series and have been examined by other studies (Breshears et al. 2005; Quiring and Goodrich 2008; Weiss et al. 2009). The periods from 1953 to 1956 and from 2000 to 2003 represent the driest 4-yr intervals during the study period and are tied to extensive drought impacts across the southwestern United States, including large-scale vegetation mortality, impacts on local water resources, and exceptionally large wildfires (Neilson 1986; Allen and Breshears 1998; Swetnam and Betancourt 1998; Breshears et al. 2005; Weiss et al. 2009). Several of these studies note that the more recent drought in the early 2000s was warmer than the 1950s drought period, exacerbating drought impacts (Breshears et al. 2005; Weiss et al. 2009). A comparison of HCEI values highlights that the intra-annual hydroclimatic variability was substantially different between these two drought periods as well. HCEI values were below 2.5 for each year from 1953 to 1956 and above 2.5 for three of four years in the 2000-03 period, reflecting a higher level of hydroclimatic extremes during this later drought period. The higher HCEI values in 2000-03 are driven by a combination of longer dry spells (CDD), higher 1- and 5-day precipitation extremes (RX1day and RX5day), and shifts in P50DAY to later dates relative to the 1950s drought period (Figs. 3a-f). The HCEI values for the driest years in each of these periods, 1.5 in 1956 and 3.9 in 2002, highlight that dry years can have dramatically different pathways to receiving their respective annual totals, which would lead to different types of emergent drought impacts throughout the year. For example, a shift toward increased cool-season precipitation could signal better soil moisture conditions at the beginning of the growing season and an increased chance of recharging local 


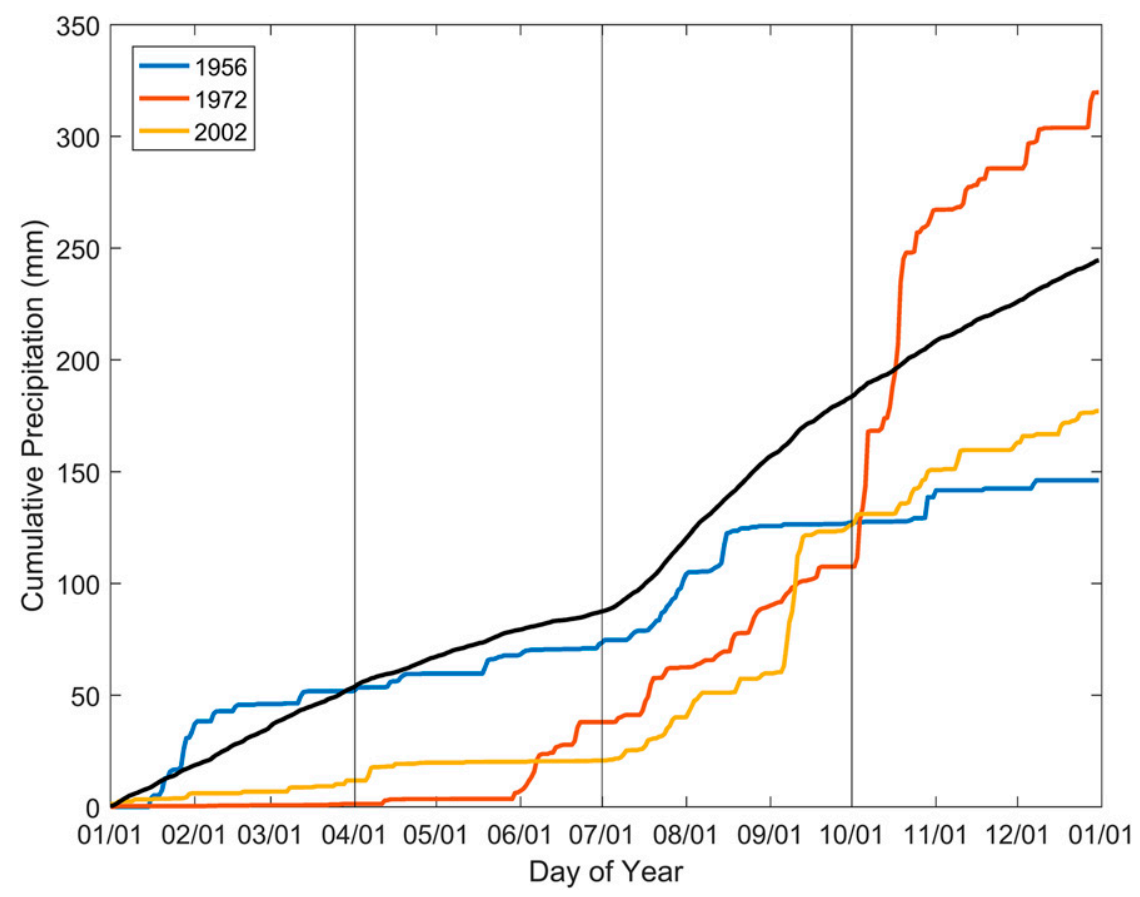

FIG. 5. Regional composite daily cumulative precipitation from 1 January through 31 December for 1956 (blue line), 1972 (red line), and 2002 (yellow line) along with the period average (black line).

water resources. In contrast, a shift toward later P50DAY values could signal both poorer soil moisture conditions as well as later onset of warm-season grass growth, leading to poor range conditions. The combination of long dry spells and heavy intervening rain events also would lead to poor soil moisture at critical times within the year but may add up to near- or even above-average precipitation totals.

Figure 5 shows the regional composite cumulative precipitation curves for 1956 and 2002. The year 1956 was drier overall than 2002 but had a more even accumulation of precipitation throughout the year, with even a short period of above-average precipitation early in the winter season. There were also frequent but small precipitation events through the winter, spring, and summer seasons in 1956. In contrast, 2002 was characterized by almost no winter precipitation followed by an extensive spring dry spell. By early July, 2002 had less than one-half of the precipitation that had accumulated by the same time in 1956. The accumulation of precipitation through the summer season was similar between the two years but diverged dramatically in late summer because of a single multiday weather event in 2002. A slow-moving, cutoff low pressure system brought widespread precipitation to much of the southwestern United States between 10 and 13 September 2002, quickly boosting precipitation levels across the study area (NOAA 2016). This event is captured by the above-median RX5day value for 2002, the fourth largest value in the 1950-2014 study period. This multiday precipitation event accounted for almost one-third of the annual total in 2002 and occurred relatively late in the year, well after the peak of the spring and summer growing seasons relative to local ecosystems and agricultural systems. Drought impacts occurring from the exceptionally dry conditions in the winter and spring would have already occurred and would not have been relieved by this late and intense event. The annual total in 2002 is higher than that in 1956, but the pattern of precipitation alone in 2002 would conceivably lead to lower soil moisture conditions and more drought stress at critical times of the year. Considering only annual precipitation in characterizing drought conditions among these years would miss the elements of precipitation timing, frequency, and intensity critical to understanding drought impacts in this region.

\section{d. The hidden drought of 1972}

The year with the most extreme HCEI value is a prime example to show that total precipitation alone can be a misleading drought metric. Annual precipitation in 1972 was $319 \mathrm{~mm}$, one of the top 10 wettest years in the 1950 2014 study period, but the year also had an HCEI value of 4.9 , very near the theoretical maximum of 5 . This means that all five of the individual hydroclimatic extremes indices were near their maximum percentile values in 1972. 
Figure 5 shows the cumulative precipitation curve for 1972 to illustrate the extreme nature of the hydroclimatic variability during this year; 1972 was much drier and had longer dry spells than both 1956 and 2002 in the winter and spring seasons. By the end of August, 1972 was only slightly wetter than 1956 . Similar to 2002 , but in a much more extreme manner, a series of short-term weather events through October, including the landfall of Tropical Storm Joanne and a slow-moving, cutoff low pressure system, brought widespread heavy rains to the region, rapidly pushing cumulative precipitation values to muchabove-average values in a matter of days (Hereford and Webb 1992; Phillips and Thomas 2005). The late timing of this precipitation again masks the drought impacts that most likely emerged across the region earlier in the winter and spring seasons. The drought in Arizona was highlighted in a CBS Evening News broadcast from 18 May 1972 in which it was reported that Phoenix, Arizona, was enduring a dry spell of 141 days, that a large wildfire was being fought by U.S. Air Force water tankers near Prescott, Arizona, and that ranchers across the region were selling off most of their livestock herds (https:// tvnews.vanderbilt.edu/broadcasts/223023). These same drought conditions were present across the Four Corners region, and therefore it was most likely experiencing very similar impacts. The extreme nature of the "catch up" precipitation through October also most likely limited its effectiveness in recharging soil moisture and improving drought conditions related to longer-term deficits. Extreme-precipitation events related to tropical storms and, from a more general perspective, instances of tropical moisture interacting with synoptic disturbances are not uncommon across the southwestern United States in the autumn season (Hirschboeck 1991; Wood and Ritchie 2013). Hydroclimatic extremes indices can be useful in identifying situations in which events like these have made disproportionately large, early, or late contributions to annual total precipitation amounts.

\section{Temperature, drought, and hydroclimatic extremes}

The role of increasing temperatures on drought stress has been widely explored in historical analysis and with climate projections suggesting that increasing temperatures will lead to higher potential evapotranspiration rates and increasing levels of aridity across the southwestern United States (Woodhouse et al. 2010; Williams et al. 2013; Cook et al. 2015). Interpreting the hydroclimatic extremes indices in conjunction with precipitation and temperature lends further insight into potential drought conditions and impacts that could emerge at the subannual scale. Figure 6, a scatterplot of HCEI values versus
PCPTOT percentiles and shaded by annual temperature percentiles, visualizes different dimensions of hydroclimatic variability and highlights years with different potential "flavors" of drought. In general, the most extreme drought years on the basis of annual precipitation totals during the 1950-2014 period had HCEI values below 2.5 (Fig. 6, lower-left quadrant) but were a mix of low and high temperature percentiles. The year 1950 stands out as the driest and near-warmest year but has a relatively low HCEI value, indicating a relatively straightforward interpretation of potential drought stress and impacts incurred through warm temperatures and overall low precipitation. In contrast, 2002 stands out as not only being warm and dry but exhibiting a relatively high HCEI value, as discussed earlier, with latent impacts that are not readily discernible from examining precipitation and temperature interactions alone. There are several other years in the lower-right quadrant of Fig. 6 that are characterized by below-median precipitation and $>2.5 \mathrm{HCEI}$ values that are a mix of warm and cool years but may have latent drought impacts related to shifts in timing, intensity, and frequency of precipitation that would warrant further investigation in identifying historical drought events. For example, 1962 and 2003 are very similar in terms of drought magnitude and HCEI values but are very different in terms of temperature, with 1962 being cooler than 2003. Temperature as a metric alone would suggest that 2003 was worse in terms of drought stress simply because of higher levels of potential evapotranspiration, but the HCEI suggests that they may be more similar in terms of soil moisture status throughout the year, driven by the frequency, intensity, and timing of precipitation events. The inclusion of an index that examines subannual hydroclimatic extremes is a simple way to diagnose potential impacts on soil moisture status and the annual water balance as a complementary way to track drought conditions in highly variable, seasonal climates.

\section{Summary and conclusions}

We used a suite of climate extremes indices to investigate historical hydroclimatic variability across tribal lands of the Four Corners region in the southwestern United States over the period of 1950-2014. The individual indices along with a combined index (HCEI) provided additional insight into intra-annual hydroclimatic variability, which is important in diagnosing potential drought impacts relevant to regional resource-management concerns. In particular, the early 1950s drought and early 2000s drought were found to have different intra-annual precipitation patterns, representing different flavors of drought and presumably different types of impacts. Shifts in the timing, intensity, and frequency of precipitation in 


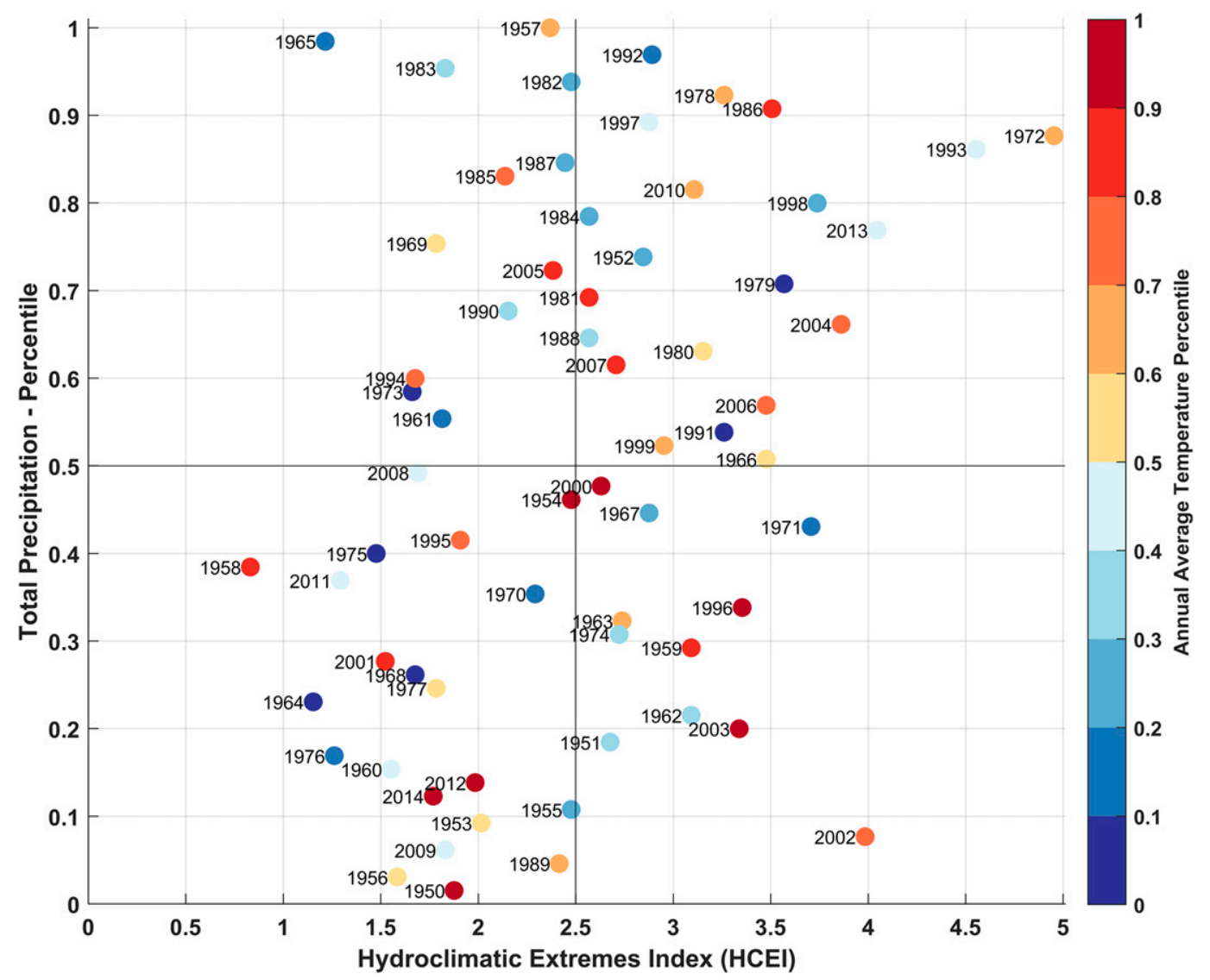

FIG. 6. Relationship of percentile rank for annual total precipitation, HCEI, and percentile rank for annual average temperature to each other.

this region can lead to direct impacts on ecosystems, local water resources, and agricultural systems that are tightly coupled with seasonal cycles in precipitation, temperature, and resulting soil moisture status.

Quantifying intra-annual hydroclimatic variability using daily-resolution precipitation data offers a simple strategy to diagnose complex drought situations in arid and semiarid regions like the Four Corners, where soil moisture monitoring is virtually nonexistent. The use of climate extremes indices retrospectively and the development of the annual HCEI, as described in this study, have the disadvantage that they cannot be used for realtime operational drought monitoring directly. However, our findings highlight the value of considering daily-scale hydroclimatic variability in identifying and characterizing potential drought conditions. This retrospective approach can, though, be used to enhance historical drought assessments in support of the development of drought plans (e.g., Wilhite et al.2000) and can help to identify extremes indices that are worth considering for operational monitoring given unique local climate conditions and droughtmonitoring needs. Some existing real-time monitoring products, such as the U.S. Geological Survey Early Warning and Environmental Monitoring Program (https://earlywarning.usgs.gov/usraindry), provide maps of rain days and dry spells, similar to metrics examined in this study that could be used to support operational drought monitoring. Developing new drought indices and monitoring products that are based on daily climate observations would further enhance drought monitoring, as illustrated in this study. Several station-based climatemonitoring products that highlight daily hydroclimatic variability have been developed for the southwestern United States (e.g., cool-season climate summaries; http:// cals.arizona.edu/climate/misc/CoolSeason/CoolSeason_ summaries.html) and are being used to support operational drought monitoring across the region.

The use of these climate extremes indices has also illustrated that complex pathways to drought can emerge at the intra-annual scale and are not necessarily fully captured by simple metrics of total precipitation and temperature. Detecting the nuances related to seasonal shifts or frequency of precipitation events in some of these past drought situations would be difficult to do 
using an index like the Palmer drought severity index, which has implicit autocorrelation from month to month (Dai 2011), or with the multiple time scales available through the standardized precipitation index that would need to be consulted simultaneously (Vicente-Serrano and López-Moreno 2005). Drought intensity driven by warming temperatures has been illustrated in numerous studies, but intra-annual hydroclimatic variability can also drive the emergence of intense drought situations that are based on shortages in soil moisture at critical times of the year. Tools to diagnose and identify drought situations relevant to arid and semiarid regions with strong seasonality in precipitation are necessary to support resource managers and planners working in these areas. These monitoring products, when used with traditional, monthly-based drought-monitoring indices like SPI and PDSI, have provided additional and important insight into the relevant aspects of seasonal and intra-annual hydroclimatic variability that drive the emergence and amelioration of drought conditions in this region. Given that hydroclimatic variability is expected to increase in a warming climate (Giorgi et al. 2011), explicitly accounting for subseasonal and intraannual precipitation variability will be even more important for drought-monitoring efforts into the future.

Acknowledgments. The authors thank our collaborators from the Hopi Tribe Department of Natural Resources, without whom this work would not be possible. Special thanks are given to T. Crimmins for her invaluable help in reviewing and editing this manuscript, and thanks are also given for the comments and suggestions from the editor and two anonymous reviewers. This work was supported by the National Oceanic and Atmospheric Administration's Climate Program Office through Grant NA13OAR4310166 from the Regional Integrated Science and Assessment Program and Grant NA10OAR4310183 from the Sectoral Applications Research Program.

\section{REFERENCES}

Allen, C. D., and D. D. Breshears, 1998: Drought-induced shift of a forest-woodland ecotone: Rapid landscape response to climate variation. Proc. Natl. Acad. Sci. USA, 95, 14 839-14 842, doi:10.1073/pnas.95.25.14839.

Arriaga-Ramírez, S., and T. Cavazos, 2010: Regional trends of daily precipitation indices in northwest Mexico and southwest United States. J. Geophys. Res., 115, D14111, doi:10.1029/ 2009JD013248.

Balling, R. C., and S. G. Wells, 1990: Historical rainfall patterns and arroyo activity within the Zuni River drainage basin, New Mexico. Ann. Assoc. Amer. Geogr., 80, 603-617, doi:10.1111/ j.1467-8306.1990.tb00320.x.

Barnes, M. L., and Coauthors, 2016: Vegetation productivity responds to sub-annual climate conditions across semiarid biomes. Ecosphere, 7, e01339, doi:10.1002/ecs2.1339.
Booth, E. L. J., J. M. Byrne, and D. L. Johnson, 2012: Climatic changes in western North America, 1950-2005. Int. J. Climatol., 32, 2283-2300, doi:10.1002/joc.3401.

Breshears, D. D., and Coauthors, 2005: Regional vegetation die-off in response to global-change-type drought. Proc. Natl. Acad. Sci. USA, 102, 15 144-15148, doi:10.1073/pnas.0505734102.

Cayan, D. R., K. T. Redmond, and L. G. Riddle, 1999: ENSO and hydrologic extremes in the western United States. J. Climate, 12, 2881-2893, doi:10.1175/1520-0442(1999)012<2881: EAHEIT $>2.0 . \mathrm{CO} ; 2$.

Cook, B. I., T. R. Ault, and J. E. Smerdon, 2015: Unprecedented 21st century drought risk in the American Southwest and central plains. Sci. Adv., 1, e1400082, doi:10.1126/ sciadv. 1400082

Crimmins, M., N. Selover, K. Cozzetto, and K. Chief, 2013: Technical review of the Navajo Nation drought contingency plan-Drought monitoring. Climate Assessment for the Southwest Tech. Rep., 24 pp. [Available online at http://cals.arizona.edu/climate/pubs/ Navajo_Nation_Drought_Plan_Technical_Review.pdf.]

, D. B. Ferguson, J. L. Weiss, and H. Faulstich, 2015: Hopi climate: An overview to support drought monitoring and management. Climate Assessment for the Southwest Tech. Rep., 10 pp. [Available online at http://www.climas.arizona.edu/ sites/default/files/pdfclimas-report-finalprint.pdf.]

Dai, A., 2011: Characteristics and trends in various forms of the Palmer drought severity index during 1900-2008. J. Geophys. Res., 116, D12115, doi:10.1029/2010JD015541.

2013: The influence of the inter-decadal Pacific oscillation on US precipitation during 1923-2010. Climate Dyn., 41, 633-646, doi:10.1007/s00382-012-1446-5.

Davidowitz, G., 2002: Does precipitation variability increase from mesic to xeric biomes? Global Ecol. Biogeogr., 11, 143-154, doi:10.1046/j.1466-822X.2002.00271.x.

Dettinger, M. D., F. M. Ralph, T. Das, P. J. Neiman, and D. R. Cayan, 2011: Atmospheric rivers, floods and the water resources of California. Water, 3, doi:10.3390/w3020445.

Dominguez, S., and K. E. Kolm, 2005: Beyond water harvesting: A soil hydrology perspective on traditional southwestern agricultural technology. Amer. Antiq., 70, 732-765, doi:10.2307/ 40035872.

Draut, A. E., M. H. Redsteer, and L. Amoroso, 2012: Vegetation, substrate, and eolian sediment transport at Teesto Wash, Navajo Nation, 2009-2012. U.S. Geological Survey Rep. 2012-5095, 71 pp. [Available online at http://pubs.usgs.gov/sir/2012/5095/.]

Faulstich, H. L., C. A. Woodhouse, and D. Griffin, 2013: Reconstructed cool- and warm-season precipitation over the tribal lands of northeastern Arizona. Climatic Change, 118, 457-468, doi:10.1007/s10584-012-0626-y.

Ferguson, D. B., C. Alvord, M. Crimmins, M. H. Redsteer, C. McNutt, M. Hayes, M. Svoboda, and R. Pulwarty, 2011: Drought preparedness for tribes in the Four Corners region. Climate Assessment for the Southwest Rep., 36 pp. [Available online at http://www.climas.arizona.edu/sites/default/files/ pdffour-corners-drought-preparedness-2011.pdf.]

- A. Masayesva, A. M. Meadow, and M. A. Crimmins, 2016: Rain gauges to range conditions: Collaborative development of a drought information system to support local decisionmaking. Wea. Climate Soc., 8, 345-359, doi:10.1175/ WCAS-D-15-0060.1.

Finger, T., and B. Morehouse, 2007: River of change: An environmental history of climate and water management in the upper Little Colorado watershed. J. Southwest, 49, 531-560, doi:10.1353/jsw.2007.0019. 
Giorgi, F., E.-S. Im, E. Coppola, N. S. Diffenbaugh, X. J. Gao, L. Mariotti, and Y. Shi, 2011: Higher hydroclimatic intensity with global warming. J. Climate, 24, 5309-5324, doi:10.1175/ 2011JCLI3979.1.

Gremer, J. R., J. B. Bradford, S. M. Munson, and M. C. Duniway, 2015: Desert grassland responses to climate and soil moisture suggest divergent vulnerabilities across the southwestern United States. Global Change Biol., 21, 4049-4062, doi:10.1111/gcb.13043.

Heim, R. R., 2002: A review of twentieth-century drought indices used in the United States. Bull. Amer. Meteor. Soc., 83, 1149-1165, doi:10.1175/1520-0477(2002)083<1149:AROTDI>2.3.CO;2.

Hereford, R., and R. H. Webb, 1992: Historic variation of warmseason rainfall, southern Colorado Plateau, southwestern U.S.A. Climatic Change, 22, 239-256, doi:10.1007/ BF00143030.

, - — , and S. Graham, 2002: Precipitation history of the Colorado Plateau region, 1900-2000. U.S. Geological Survey Fact Sheet 119-02, 4 pp. [Available online at http://pubs.usgs.gov/fs/ 2002/fs119-02/fs119-02.pdf.]

— - - and C. I. Longpré, 2006: Precipitation history and ecosystem response to multidecadal precipitation variability in the Mojave Desert region, 1893-2001. J. Arid Environ., 67, 13-34, doi:10.1016/j.jaridenv.2006.09.019.

Hirschboeck, K. K., 1991: Hydrology of floods and droughts: Climate and floods. In National water summary 1988-89: Hydrologic events and floods and droughts. U.S. Geological Survey Water Supply Paper 2375, 67-88. [Available online at https://pubs.usgs.gov/wsp/2375/report.pdf.]

Holden, Z. A., P. Morgan, M. A. Crimmins, R. K. Steinhorst, and A. M. S. Smith, 2007: Fire season precipitation variability influences fire extent and severity in a large southwestern wilderness area, United States. Geophys. Res. Lett., 34, L16708, doi:10.1029/2007GL030804.

Hottenstein, J. D., G. E. Ponce-Campos, J. Moguel-Yanes, and M. S. Moran, 2015: Impact of varying storm intensity and consecutive dry days on grassland soil moisture. J. Hydrometeor., 16, 106-117, doi:10.1175/JHM-D-14-0057.1.

IPCC, 2012: Managing the Risks of Extreme Events and Disasters to Advance Climate Change Adaptation. Cambridge University Press, 582 pp. [Available online at https://www.ipcc.ch/pdf/ special-reports/srex/SREX_Full_Report.pdf.]

Katz, R. W., and M. H. Glantz, 1986: Anatomy of a rainfall index. Mon. Wea. Rev., 114, 764-771, doi:10.1175/1520-0493(1986)114<0764: AOARI $>2.0 . \mathrm{CO} ; 2$.

Klein Tank, A. M. G., F. W. Zwiers, and X. Zhang, 2009: Guidelines on analysis of extremes in a changing climate in support of informed decisions for adaptation. World Meteorological Organization Rep. WCDMP-72, 52 pp. [Available online at http://www.wmo.int/pages/prog/wcp/wcdmp/wcdmp_series/ documents/WCDMP_72_TD_1500_en_1.pdf.]

Lauenroth, W. K., and J. B. Bradford, 2012: Ecohydrology of dry regions of the United States: Water balance consequences of small precipitation events. Ecohydrology, 5, 4653, doi:10.1002/eco.195.

Legates, D. R., R. Mahmood, D. F. Levia, T. L. DeLiberty, S. M. Quiring, C. Houser, and F. E. Nelson, 2011: Soil moisture: A central and unifying theme in physical geography. Prog. Phys. Geogr., 35, 65-86, doi:10.1177/0309133310386514.

Loik, M. E., D. D. Breshears, W. K. Lauenroth, and J. Belnap, 2004: A multi-scale perspective of water pulses in dryland ecosystems: Climatology and ecohydrology of the western USA. Oecologia, 141, 269-281, doi:10.1007/s00442-004-1570-y.
Mantua, N. J., S. R. Hare, Y. Zhang, J. M. Wallace, and R. C. Francis, 1997: A Pacific interdecadal climate oscillation with impacts on salmon production. Bull. Amer. Meteor. Soc., 78, 1069-1079, doi:10.1175/1520-0477(1997)078<1069: APICOW $>2.0 . C O ; 2$.

McKee, T. B., N. J. Doesken, and J. Kleist, 1995: Drought monitoring with multiple time scales. Preprints, Ninth Conf. on Applied Climatology, Dallas, TX, Amer. Meteor. Soc., 233236.

Meadow, A. M., D. B. Ferguson, and M. Crimmins, 2013: Helping a community develop a drought impacts reporting system. Rural Connections, 7 (1), 15-18. [Available online at http://wrdc.usu.edu/ files/publications/publication/pub_7956191.pdf.]

Menne, M. J., I. Durre, R. S. Vose, B. E. Gleason, and T. G Houston, 2012: An overview of the Global Historical Climatology Network-Daily database. J. Atmos. Oceanic Technol., 29, 897-910, doi:10.1175/JTECH-D-11-00103.1.

Moran, M. S., and Coauthors, 2014: Functional response of U.S. grasslands to the early 21st-century drought. Ecology, 95, 2121-2133, doi:10.1890/13-1687.1.

Neilson, R. P., 1986: High-resolution climatic analysis and southwest biogeography. Science, 232, 27-34, doi:10.1126/ science.232.4746.27.

New, M., and Coauthors, 2006: Evidence of trends in daily climate extremes over southern and West Africa. J. Geophys. Res., 111, D14102, doi:10.1029/2005JD006289.

NOAA, 2016: Daily weather maps. National Centers for Environmental Prediction Weather Prediction Center, accessed 10 June 2016. [Available online at http://www.wpc.ncep.noaa.gov/ dailywxmap/index.html.]

Noy-Meir, I., 1973: Desert ecosystems: Environment and producers. Annu. Rev. Ecol. Syst., 4, 25-51, doi:10.1146/ annurev.es.04.110173.000325.

Phillips, J. V., and B. E. Thomas, 2005: Hydrologic conditions in Arizona during 1999-2004: A historical perspective. U.S. Geological Survey Fact Sheet 2005-3081, 4 pp. [Available online at http://pubs.usgs.gov/fs/2005/3081/pdf/FS2005-3081WEB.pdf.]

Quiring, S. M., and G. B. Goodrich, 2008: Nature and causes of the 2002 to 2004 drought in the southwestern United States compared with the historic 1953 to 1957 drought. Climate Res., 36, 41-52, doi:10.3354/cr00735.

—, T. W. Ford, J. K. Wang, A. Khong, E. Harris, T. Lindgren, D. W. Goldberg, and Z. Li, 2016: The North American Soil Moisture Database: Development and applications. Bull. Amer. Meteor. Soc., 97, 1441-1459, doi:10.1175/BAMS-D-13-00263.1.

Redmond, K. T., and R. W. Koch, 1991: Surface climate and streamflow variability in the western United States and their relationship to large-scale circulation indices. Water Resour. Res., 27, 2381-2399, doi:10.1029/91WR00690.

Rhoades, E. K., 2013: The Hopi people and drought: Observations, adaptations, and stewardship in a sacred land. Ph.D. dissertation, The Johns Hopkins University, 237 pp. [Available online at https://jscholarship.library.jhu.edu/bitstream/ handle/1774.2/37047/RHOADES-DISSERTATION-2013 pdf.]

Schwinning, S., J. Belnap, D. R. Bowling, and J. R. Ehleringer, 2008: Sensitivity of the Colorado Plateau to change: Climate, ecosystems, and society. Ecol. Soc., 13, 28. [Available online at http://www.ecologyandsociety.org/vol13/iss2/art28/.]

Seager, R., and G. A. Vecchi, 2010: Greenhouse warming and the 21st century hydroclimate of southwestern North America. Proc. Natl. Acad. Sci. USA, 107, 21 277-21 282, doi:10.1073/ pnas.0910856107. 
Sheppard, P. R., A. C. Comrie, G. D. Packin, K. Angersbach, and M. K. Hughes, 2002: The climate of the U.S. Southwest. Climate Res., 21, 219-238, doi:10.3354/cr021219.

Swetnam, T. W., and J. L. Betancourt, 1998: Mesoscale disturbance and ecological response to decadal climatic variability in the American Southwest. J. Climate, 11, 3128-3147, doi:10.1175/ 1520-0442(1998)011<3128:MDAERT>2.0.CO;2.

Vicente-Serrano, S. M., and J. I. López-Moreno, 2005: Hydrological response to different time scales of climatological drought: An evaluation of the standardized precipitation index in a mountainous Mediterranean basin. Hydrol. Earth Syst. Sci., 9 523-533, doi:10.5194/hess-9-523-2005.

Weiss, J. L., C. L. Castro, and J. T. Overpeck, 2009: Distinguishing pronounced droughts in the southwestern United States: Seasonality and effects of warmer temperatures. J. Climate, 22, 5918-5932, doi:10.1175/2009JCLI2905.1.

Wilhite, D. A., M. J. Hayes, C. Knutson, and K. H. Smith, 2000: Planning for drought: Moving from crisis to risk management. J. Amer. Water Resour. Assoc., 36, 697-710, doi:10.1111/ j.1752-1688.2000.tb04299.x.
Williams, A. P., and Coauthors, 2013: Temperature as a potent driver of regional forest drought stress and tree mortality. Nat. Climate Change, 3, 292-297, doi:10.1038/nclimate1693.

Wood, K. M., and E. A. Ritchie, 2013: An updated climatology of tropical cyclone impacts on the southwestern United States. Mon. Wea. Rev., 141, 4322-4336, doi:10.1175/ MWR-D-13-00078.1.

Woodhouse, C. A., D. M. Meko, G. M. MacDonald, D. W. Stahle, and E. R. Cook, 2010: A 1,200-year perspective of 21st century drought in southwestern North America. Proc. Natl. Acad. Sci. USA, 107, 21 283-21 288, doi:10.1073/pnas.0911197107.

Zhang, X., L. Alexander, G. C. Hegerl, P. Jones, A. K. Tank, T. C. Peterson, B. Trewin, and F. W. Zwiers, 2011: Indices for monitoring changes in extremes based on daily temperature and precipitation data. Wiley Interdiscip. Rev.: Climate Change, 2, 851-870, doi:10.1002/wcc.147.

Zhang, Y., and Coauthors, 2013: Extreme precipitation patterns and reductions of terrestrial ecosystem production across biomes. J. Geophys. Res. Biogeosci., 118, 148-157, doi:10.1029/ 2012JG002136. 